\title{
Gasotransmitters: novel regulators of ion channels and transporters
}

\section{Mike Althaus* and Wolfgang G. Clauss}

Department of Molecular Cell Physiology, Institute of Animal Physiology, Justus-Liebig University of Giessen, Giessen, Germany

*Correspondence: mike.althaus@bio.uni-giessen.de

Edited by:

Mario L. Diaz, Universidad de La Laguna, Spain

More than 25 years ago, it was a big surprise for physiologists that nitric oxide (NO) was identified as the endothelium derived relaxing factor which is responsible for endothelium-induced smooth muscle relaxation (Ignarro et al., 1987). Until then, small gaseous molecules were simply regarded as byproducts of cellular metabolism which were unlikely to be of any physiological relevance. The discovery that NO was synthesized by specific enzymes (NO-synthases), upon stimulation by specific, physiologically relevant stimuli (e.g., acetylcholine stimulation of endothelial cells), as well as the fact that it acted on specific cellular targets (e.g., soluble guanylate cyclase), set the course for numerous studies which investigated the physiological roles of gaseous signaling molecules-in other words, gasotransmitters (Wang, 2002).

Aside from NO, there are two more gases which subsequently have been identified as gasotransmitters: carbon monoxide (CO) (Wu and Wang, 2005) and hydrogen sulfide $\left(\mathrm{H}_{2} \mathrm{~S}\right)$ (Abe and Kimura, 1996; Wang, 2002). Although the concept of a gas being involved in cellular signaling processes was already accepted since the discovery of $\mathrm{NO}$, the new candidates $\mathrm{CO}$ and $\mathrm{H}_{2} \mathrm{~S}$ were initially met with skepticism-especially since they were well-known for their high toxicity and regarded as environmental chemical threats. However, in concert with the principle of Paracelsus that "everything is toxic- it just depends on the dose," it is nowadays accepted that small amounts of $\mathrm{CO}$ and $\mathrm{H}_{2} \mathrm{~S}$ are of physiological relevance and are even endogenously produced in human cells (Wu and Wang, 2005; Wang, 2012).

All three gasotransmitters are produced in human cells by specific enzymes: NO is produced by NO-synthases (NOS), originating from the amino acid L-arginine. There are three NOS-isoforms, NOS1-3, which have been originally termed neuronal, inducible and endothelial NOS, respectively (Garvin et al., 2011). CO is generated by heme oxygenases (HO) within heme degradation ( $\mathrm{Wu}$ and Wang, 2005). There are also three heme oxygenases (HO-1-3) (Yoshida et al., 1974; Maines et al., 1986; McCoubrey et al., 1997), including an inducible $\mathrm{HO}-1$ and a constitutively active $\mathrm{HO}-2 . \mathrm{H}_{2} \mathrm{~S}$ is mainly produced within the metabolism of L-cysteine by the enzymes cystathionine- $\beta$-synthase (CBS), cystathionine- $\gamma$ lyase (CSE or CTH) and 3-mercaptopyruvate sufurtransferase (3-MST) (Wang, 2012). Recently, Kimura's group described an additional pathway for endogenous $\mathrm{H}_{2} \mathrm{~S}$ production, which involves D-cysteine, 3-MST, and D-amino acid oxidase (Shibuya et al., 2013).
Despite the knowledge of the substrates and specific enzymes which are involved in gasotransmitter production, the precise endogenous concentrations of $\mathrm{NO}, \mathrm{CO}$, and $\mathrm{H}_{2} \mathrm{~S}$ have still not been sufficiently determined. The measurement of endogenous gas concentrations is limited by the accuracy and specificity of currently available methods (Olson, 2013), the reactivity and short half-life of some gases (NO) (Wall et al., 2012), and simply the fact that gases are volatile and rapidly disappear during the preparation procedures of biological samples. As highlighted within this research topic issue, it is crucial—and probably most challenging - to precisely quantify endogenous concentrations of NO, CO, and $\mathrm{H}_{2} \mathrm{~S}$ (Kimura, 2012; Peers, 2012; Olson, 2013).

Although precise endogenous concentrations of gasotransmitters remain to be determined, numerous studies investigated the physiological effects of those gaseous signaling molecules in almost every organ system [as summarized in excellent review articles such as Olson (2011), Wu and Wang (2005), and Wang (2012)]. Common molecular targets for all gasotransmitters are ion channels and transporters. Changes in the activity of membrane-located ion channels/transporters are involved in the majority of physiological processes which are regulated by gasotransmitters. This allows the gases to specifically act at the interface of cell-environment interactions, electrolyte homeostasis and electrochemical communication-thus allowing the regulation of numerous physiological processes in cells and tissues.

This research topic summarizes currently available data on the regulation of ion channels and transporters by $\mathrm{NO}, \mathrm{CO}$, and $\mathrm{H}_{2} \mathrm{~S}$. Excellent review and research articles highlight the importance of gasotransmitter/ion channel interactions for vegetative physiology (Althaus, 2012; Peers, 2012; Pouokam and Diener, 2012), neurophysiology (Njie-Mbye et al., 2012; Peers, 2012; Takahashi et al., 2012; Wang et al., 2012), and explain gasotransmitterinduced signaling mechanisms (Wall et al., 2012). Furthermore, opinion articles from pioneers in gasotransmitter research (Kimura, 2012; Peers, 2012; Olson, 2013) give perspectives on important routes which should be followed in this field. With the articles included in this issue we wish to highlight the importance of ion channel/transporter regulation by gaseous signaling molecules and wish to stimulate future research in this exciting area of physiology.

\section{ACKNOWLEDGMENTS}

The editors thank all authors and colleagues for their outstanding contributions to this Frontiers Research Topic. 


\section{REFERENCES}

Abe, K., and Kimura, H. (1996). The possible role of hydrogen sulfide as an endogenous neuromodulator. J. Neurosci. 16, 1066-1071.

Althaus, M. (2012). Gasotransmitters: novel regulators of epithelial $\mathrm{Na}(+)$ transport? Front. Physio. 3:83. doi: 10.3389/fphys.2012.00083

Garvin, J. L., Herrera, M., and Ortiz, P. A. (2011). Regulation of renal $\mathrm{NaCl}$ transport by nitric oxide, endothelin, and ATP: clinical implications. Annu. Rev. Physiol. 73, 359-376.

Ignarro, L. J., Buga, G. M., Wood, K. S., Byrns, R. E., and Chaudhuri, G. (1987). Endothelium-derived relaxing factor produced and released from artery and vein is nitric oxide. Proc. Natl. Acad. Sci. U.S.A. 84, 9265-9269.

Kimura, H. (2012). Metabolic turnover of hydrogen sulfide. Front. Physio. 3:101. doi: 10.3389/fphys. 2012.00101

Maines, M. D., Trakshel, G. M., and Kutty, R. K. (1986). Characterization of two constitutive forms of rat liver microsomal heme oxygenase. Only one molecular species of the enzyme is inducible. J. Biol. Chem. 261, 411-419.
McCoubrey, W. K., Huang, T. J., and Maines, M. D. (1997). Isolation and characterization of a cDNA from the rat brain that encodes hemoprotein heme oxygenase-3. Eur. J. Biochem. 247, 725-732.

Njie-Mbye, Y. F., Opere, C. A., Chitnis, M., and Ohia, S. E. (2012). Hydrogen sulfide: role in ion channel and transporter modulation in the eye. Front. Physio. 3:295. doi: 10.3389/fphys.2012.00295

Olson, K. R. (2011). The therapeutic potential of hydrogen sulfide: separating hype from hope. Am. J. Physiol. Regul. Integr. Comp. Physiol. 301, R297-R312.

Olson, K. R. (2013). Hydrogen sulfide: both feet on the gas and none on the brake? Front. Physio. 4:2. doi: 10.3389/fphys.2013.00002

Peers, C. (2012). Modulation of ion channels and transporters by carbon monoxide: causes for concern? Front. Physio. 3:477. doi: 10.3389/fphys.2012.00477

Pouokam, E., and Diener, M. (2012). Modulation of ion transport across rat distal colon by cysteine. Front. Physio. 3:43. doi: 10.3389/fphys.2012.00043

Shibuya, N., Koike, S., Tanaka, M. Ishigami-Yuasa, M., Kimura, Y.,
Ogasawara, Y., et al. (2013). A novel pathway for the production of hydrogen sulfide from D-cysteine in mammalian cells. Nat. Commun. 4:1366. doi: $10.1038 /$ ncomms 2371

Takahashi, N., Kozai, D., and Mori, Y. (2012). TRP channels: sensors and transducers of gasotransmitter signals. Front. Physio. 3:324. doi: 10.3389/fphys.2012 00324

Wall, S. B., Oh, J.-Y., Diers, A. R., and Landar, A. (2012). Oxidative modification of proteins: an emerging mechanism of cell signaling. Front. Physio. 3:369. doi: 10.3389/fphys. 2012.00369

Wang, J. Q., Chu, X.-P., Guo, M.L., Jin, D.-Z., Xue, B., Berry, T. J., et al. (2012). Modulation of ionotropic glutamate receptors and Acid-sensing ion channels by nitric oxide. Front. Physio. 3:164. doi: 10.3389/fphys.2012. 00164

Wang, R. (2002). Two's company, three's a crowd: can H2S be the third endogenous gaseous transmitter? FASEB J. 16, 1792-1798.

Wang, R. (2012). Physiological implications of hydrogen sulfide: a whiff exploration that blossomed. Physiol. Rev. 92, 791-896.
Wu, L., and Wang, R. (2005). Carbon monoxide: endogenous production, physiological functions, and pharmacological applications. Pharmacol. Rev. 57, 585-630.

Yoshida, T., Takahashi, S., and Kikuchi, G. (1974). Partial purification and reconstitution of the heme oxygenase system from pig spleen microsomes. J. Biochem. 75, 1187-1191.

Received: 05 February 2013; accepted: 05 February 2013; published online: 21 February 2013.

Citation: Althaus $M$ and Clauss WG (2013) Gasotransmitters: novel regulators of ion channels and transporters. Front. Physio. 4:27. doi: 10.3389/fphys. 2013.00027

This article was submitted to Frontiers in Membrane Physiology and Biophysics, a specialty of Frontiers in Physiology.

Copyright (c) 2013 Althaus and Clauss. This is an open-access article distributed under the terms of the Creative Commons Attribution License, which permits use, distribution and reproduction in other forums, provided the original authors and source are credited and subject to any copyright notices concerning any third-party graphics etc. 